\title{
Malignant transformation of mature cystic teratoma of the ovary including three cases occurring during follow-up period
}

\author{
KEN YAMAGUCHI, MASAKI MANDAI, KEN FUKUHARA, TOSHIHIRO HIGUCHI, \\ JUNZO HAMANISHI, KENJI TAKAKURA and SHINGO FUJII
}

\begin{abstract}
Department of Gynecology and Obstetrics, Graduate School of Medicine, Kyoto University, Kyoto 606-8507, Japan
\end{abstract}
Received June 27, 2007; Accepted September 28, 2007

\begin{abstract}
The aim of this study was to seek for factors which lead to the early diagnosis of malignant transformation from mature cystic teratoma. Fourteen patients with malignant transformation from mature cystic teratoma of the ovary were analyzed retrospectively for precise clinicopathology and prognosis. The results demonstrated that although all the patients with stage Ia disease were disease-free, only 2 out of 7 patients were stage Ic to IV and disease-free in the follow-up period. Pre-operative imaging correctly diagnosed tumors as malignant in all stage Ic to IV cases, but only in 2 out of 4 stage Ia cases with magnetic resource and none of the 2 cases with computed tomography, respectively. In malignant cases, elevation of the serum SCC and CEA was observed in 90.9 and $88.9 \%$, respectively. On the other hand, in benign cases, a false positive elevation of the serum SCC and CEA was observed in 23.5 and $14.3 \%$, which turned out to be normal in 40 and $52.9 \%$ cases in the repeated study, respectively. In conclusion neither imaging analysis nor tumor markers including SCC and CEA accurately diagnose malignant transformation of mature cystic teratoma in its early stage, suggesting that a combination of diagnostic means is important. In the followup cases, repeated measurement of serum markers proved useful in ruling out false positive cases.
\end{abstract}

\section{Introduction}

Mature cystic teratoma of the ovary is one of the most common benign tumors among reproductive women which accounts for $10-20 \%$ of benign ovarian cysts (1) and $70 \%$ of benign ovarian neoplasm among women younger than 30 years (2). In contrast, the malignant transformation of mature cystic teratoma, usually present as a squamous cell carcinoma, occurs only in $1-2 \%$ of the cases (3-6). It is well known that

Correspondence to: Dr Masaki Mandai, Department of Gynecology and Obstetrics, Graduate School of Medicine, Kyoto University, Kyoto 606-8507, Japan

E-mail: mandai@kuhp.kyoto-u.ac.jp

Key words: mature cystic teratoma, dermoid cyst, malignant transformation, ovarian tumor clinically advanced cases with squamous cell carcinoma arising from mature cystic teratoma have poor prognosis partly because of its poor response to chemotherapy. Unfortunately, two-thirds of these patients are admitted at an advanced stage accompanied with invasion or metastasis at the time of diagnosis, as is the case with most of the ovarian cancers $(7,8)$. Surgical removal is the best treatment to prevent mature cystic teratoma from malignant transformation but not all of the patients accept surgical treatment. Therefore, it is important to seek the means at early diagnosis of malignant transformation when it occurs in the follow-up course of mature cystic teratoma. Here, we retrospectively analyzed the pre-operative findings of 14 cases of ovarian carcinoma arising from mature cystic teratoma at Kyoto University Hospital. Three of them occurred during the follow-up of mature cystic teratoma.

\section{Materials and methods}

From 1985 to 2005 , fourteen patients with malignant transformation from mature cystic teratoma of the ovary were treated at Kyoto University Hospital. All tumors were histologically classified according to the World Health Organization (WHO) criteria. Clinical staging was performed according to the International Federation of Obstetrics and Gynecology (FIGO) criteria. Pre-operative investigations included a gynecological examination, chest X-ray, tumor markers, transvaginal ultrasonography, computed tomography (CT) and magnetic resource imaging (MRI). Tumor markers including SCC, CEA, CA125 and CA19-9 were measured pre-operatively. The treatment was based on hysterectomy, bilateral salpingo-oophorectomy, lymphadenectomy and cytoreduction and adjuvant therapies were determined according to the clinical stage and pathological risk. A secondlook operation was not routinely performed except for the cases with suspected residual or recurrent tumors. A follow-up examination included a physical examination, tumor markers, transvaginal ultrasonography and a CT.

\section{Case reports}

Case 1. The patient (No. 6 in Tables I and II) was a 48-yearold nullipara introduced to our hospital due to a large ovarian mass. An ovarian mass was pointed out five years earlier, which was diagnosed as a dermoid cyst by CT, MRI and 
a)

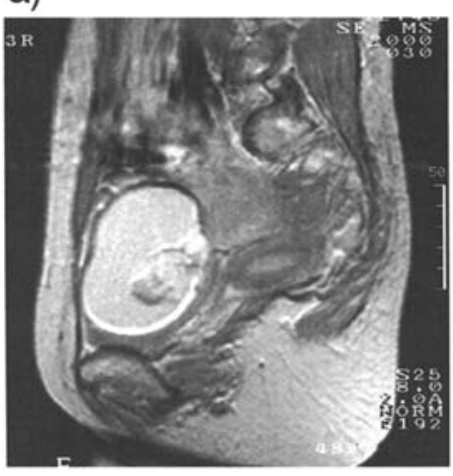

c-1)



b)

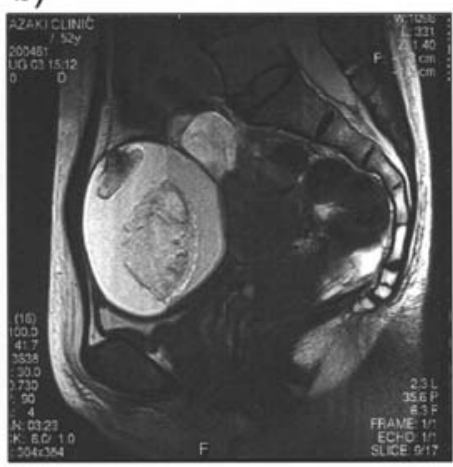

c-2)



d)

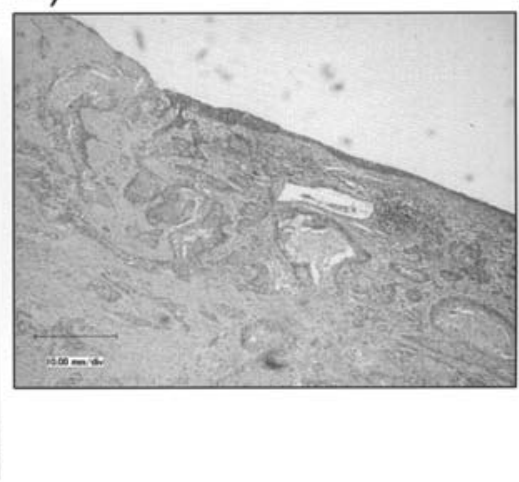

Figure 1. MRI and pathological findings of case 1 (patient No. 6). (a) Enhanced T2-weighted image (T2WI) at 5 years before the operation shows a tumor of $7 \mathrm{~cm}$ in diameter with chemical shift artifact. (b) T2WI at 2 years before the operation shows a slightly increased size of the tumor, but no apparent malignant finding. (c) Pre-operative MRI of T1WI and enhanced T1WI with fat-suppression show the tumor at $14 \mathrm{~cm}$ in diameter. The size increased prominently and an enhanced solid component appeared. (d) The pathological finding shows keratinizing squamous cell carcinoma with stromal invasion. Internal scale: 10 mm.

ultrasonography (Fig. 1a and b). The patient experienced hypogastric pain for a month before attending hospital. A CT and MRI revealed an increase in the tumor size and appearance of a solid part that was not detected 5 years ago (Fig. 1c). The tumor marker SCC was markedly elevated. A total abdominal hysterectomy and bilateral salpingooophorectomy along with pelvic and para-aortic lymphadenectomy were performed. Bilateral ovaries were cystically enlarged and microscopically squamous cell carcinoma was detected only in the right ovary (stage Ia, Fig. 1d). The patient underwent 3 courses of adjuvant docetaxel and carboplatin chemotherapy. She has been free of disease for 17 months since the operation.

Case 2. A 29-year-old pregnant woman (No.12 in Tables I and II) underwent left salpingo-oophorectomy due to a twisted ovarian cyst in her 12th week of gestation. The histology was mature cystic teratoma. Intraoperative exploration revealed a seemingly normal right ovary. She subsequently bore a baby at full term in normal vaginal delivery without any complications. Six weeks after delivery (8 months after the first laparotomy), she came to the hospital for postoperative follow-up and a right ovarian cyst $11 \mathrm{~cm}$ in diameter was found. She was followed up for 3 months because of her strong aversion to the recommendation of surgical intervention. She noticed increasing abdominal fullness 3 months later and an exploratory laparotomy was performed. Intraoperative findings included a right ovarian mass of $15 \mathrm{~cm}$ in diameter and intraperitoneal dissemination in the omentum, small intestine, uterus and the surface of the peritoneum. Pathological findings consisted of squamous cell carcinoma in the right ovary and in the omental metastatic foci and right salpingo-oophorectomy, omentectomy and appendectomy were performed, but a minimal lesion $(3 \mathrm{~cm}$ maximum in diameter) resided (Fig. 2d). An intraperitoneal administration of cisplatin (70 mg) was performed, followed by another intraperitoneal administration of cisplatin $(100 \mathrm{mg})$ three weeks later. A second-look laparotomy was performed one month after the previous operation, which revealed no apparent lesion. Another intraperitoneal administration of cisplatin $(120 \mathrm{mg}$ ) and two courses of a VAB-6 regimen (cisplatin $120 \mathrm{mg}$, cyclophosphamide $500 \mathrm{mg}$, vinblastine $5 \mathrm{mg}$, actinomycin D $1 \mathrm{mg}$, pepleomycin $40 \mathrm{mg}$ ) were added. The patient has been free of disease for 7 years.

Case 3. A 59 year-old multipara (No.14 in Tables I and II) was referred to our hospital due to a left ovarian tumor. She had been suffering from chronic renal failure and underwent periodical dialysis. The CT, MRI and vaginal ultrasound indicated a cystic mass of $4 \mathrm{~cm}$ in the left ovary (Fig. 2a). These findings were consistent with benign mature teratoma and were further confirmed by normal serum levels of tumor markers including SCC and CEA. Considering the patient's general condition, operative intervention was withheld and a periodical check-up by CT scan was chosen. Subsequently, she was closely followed up for 3 years until she stopped seeing us. Five years after the first diagnosis, she visited a 
a)

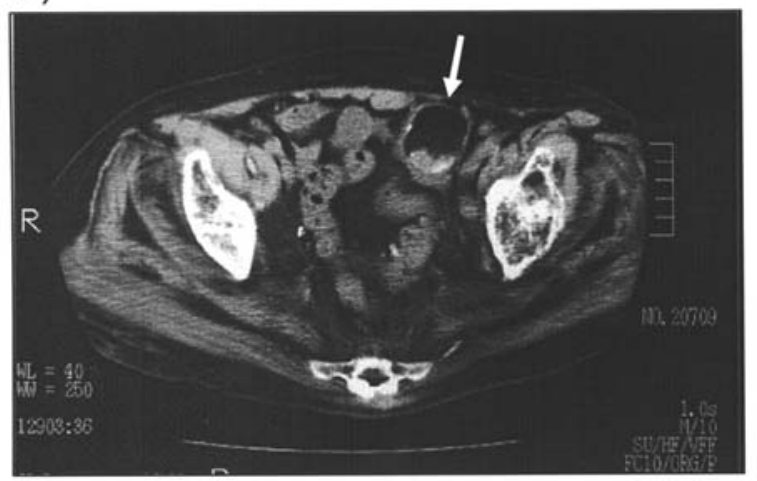

c)

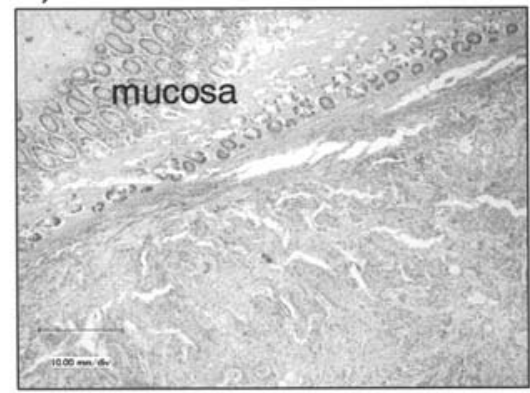

b)

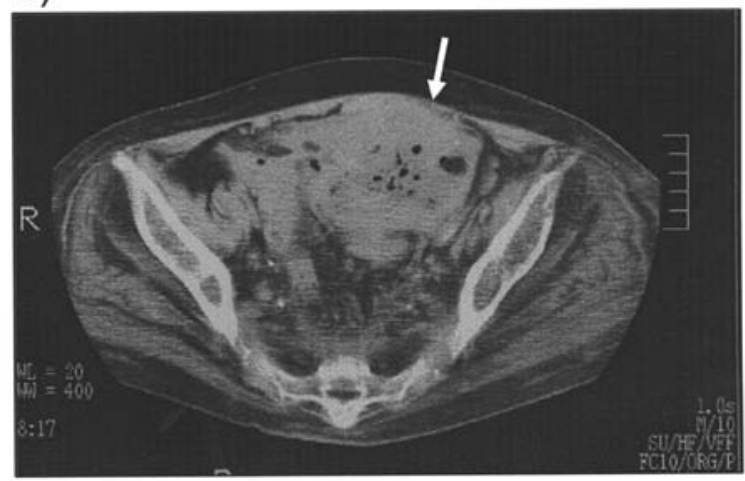

d)

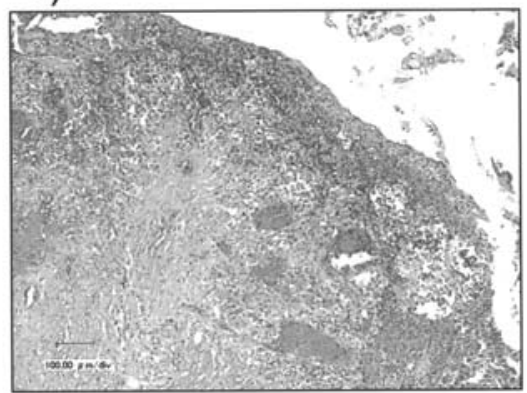

Figure 2. CT and pathological findings of case 3 (patient No.14). (a) CT at 2 years before the operation shows a tumor of $4 \mathrm{~cm}$ in diameter with calcification in the right ovary (arrow). (b) Pre-operative CT shows a tumor of $10 \mathrm{~cm}$ in diameter containing air (arrow). (c) The pathological finding shows squamous cell carcinoma invading close to the colonic mucosa. Internal scale: $10 \mathrm{~mm}$. (d) The pathological finding of case 2 (patient No.12) consisted of squamous cell carcinoma in the right ovary. Internal scale: $100 \mu \mathrm{m}$.

nearby hospital due to abdominal pain and was referred to our hospital. She was admitted with abdominal pain with acute peritoneal symptoms. An emergency CT suggested a left ovarian mass of $8 \mathrm{~cm}$ in diameter and bowel perforation (Fig. 2b). Exploratory laparotomy revealed severe panperitonitis caused by the penetration of a right ovarian tumor to the descending colon and leakage of the bowel contents. A pathological examination revealed squamous cell carcinoma invading close to the colonic mucosa. A hysterectomy with bilateral salpingo-oophorectomy and a left hemi-colectomy was performed. The patient died of the rapidly progressive disease 4 months later.

\section{Results}

The median age of these 14 patients was 50.2 years (range, 29-67 years). During a four-year period beginning in November 2000, we had 112 cases of benign mature cystic teratomas whose median age was 35.1 years, resulting in an occurrence frequency of $\sim 2.5 \%$. The malignant cases consisted of 9 stage I (7 stage Ia and 2 stage Ic), one stage II, 3 stage III and one stage IV cases. The result of pre-operative investigations including chief complaints and the tumor markers, CT and MRI, are listed in Table I. Most of the cases include abdominal distention and sensation of an abdominal mass reflecting large tumor size. Pre-operative imaging analysis correctly diagnosed malignant cases as malignant in all the cases with Ic to IV stages, while only 2 out of 4 cases and none of 2 cases of stage Ia disease were diagnosed as malignant with MRI and CT, respectively.
Table II shows operative findings, post-operative treatment and prognosis of the malignant cases. The tumor sizes exceeded $10 \mathrm{~cm}$ in diameter in both the early and advanced cases (range, 10-30 cm). Pathological diagnoses were squamous cell carcinoma in 11 patients, transitional cell carcinoma in 1 case, serous papillary adenocarcinoma in 1 case and clear cell carcinoma in 1 case. Hysterectomy, bilateral salpingo-oophorectomy and cytoreduction were performed in the majority of the cases. Adjuvant chemotherapy with cisplatium-based regimens was employed according to the clinical situation. Regarding the prognosis, all the patients with stage Ia disease were free of the disease at this point whereas only two patients in more advanced stages than Ic were free of the disease. The two-dimensional plot with the patients' age ( $>45$ years old) and tumor size $(>10 \mathrm{~cm}$ diameter) demonstrates that the sensitivity and the specificity for malignancy using these two factors was 92.9 and $98 \%$, respectively (Fig. 3). There was only one case $<45$ years of age. However, the tumor size was $\geq 10 \mathrm{~cm}$ in diameter in all the cases. Fig. 4 compares the serum tumor markers between the 14 malignant and benign cases. The number of each benign case is 136 for SCC, 133 for CEA, 138 for CA125 and 139 for CA19-9. In the malignant cases, elevation of the serum SCC, CEA, CA125 and CA19-9 were found in 10 out of $11(90.9 \%)$ cases, 8 out of $9(88.9 \%)$ cases, 9 out of 9 $(100 \%)$ cases and 8 out of $10(80 \%)$ cases, respectively. In the benign cases, elevation of the serum marker was found in 32 out of $136(23.5 \%)$ for SCC, 19 out of 133 (14.3\%) for CEA, 57 out of 138 (41.3\%) for CA125 and 66 out of 139 $(47.5 \%)$ for CA19-9. In 30 of the benign cases in which SCC 
Table I. Pre-operative findings including chief complaints, tumor markers, computed tomography (CT) and magnetic resource imaging (MRI) in malignant cases.

\begin{tabular}{|c|c|c|c|c|c|c|c|c|}
\hline $\begin{array}{l}\text { Patient } \\
\text { No. }\end{array}$ & $\begin{array}{l}\text { Age } \\
\text { (years) }\end{array}$ & Stage & Chief complaint & $\begin{array}{l}\text { CT or MR } \\
\text { appearance }\end{array}$ & $\begin{array}{l}\mathrm{SCC} \\
(\mathrm{ng} / \mathrm{ml})\end{array}$ & $\begin{array}{l}\text { CEA } \\
(\mathrm{ng} / \mathrm{ml})\end{array}$ & $\begin{array}{l}\text { CA125 } \\
(\mathrm{U} / \mathrm{ml})\end{array}$ & $\begin{array}{l}\text { CA19-9 } \\
(\mathrm{U} / \mathrm{ml})\end{array}$ \\
\hline 1 & 46 & Ia & $\begin{array}{l}\text { Lower abdominal pain } \\
\text { Abdominal distension } \\
\text { Abdominal mass }\end{array}$ & MCT & 5.6 & 34.8 & 40 & 510 \\
\hline 2 & 46 & Ia & Abdominal mass & - & - & 1.4 & 162 & 350 \\
\hline 3 & 48 & Ia & Amenorrhea & MCT & 6.9 & - & 41 & 187 \\
\hline 4 & 63 & Ia & Abdominal distension & MCT & - & 2.5 & 125 & - \\
\hline 5 & 50 & Ia & Abdominal distension & $\mathrm{MCT}$ & 18.7 & 11.1 & 109.8 & 7.3 \\
\hline 6 & 53 & Ia & Lower abdominal pain & MCT-MT & 28.4 & 2.5 & 93.9 & 132.8 \\
\hline 7 & 48 & Ia & Abdominal distension & MCT-MT & 9.4 & - & - & - \\
\hline 8 & 47 & Ic & $\begin{array}{l}\text { Lower abdominal pain } \\
\text { Abdominal mass }\end{array}$ & MCT-MT & 3.3 & 27.5 & 22 & 4150 \\
\hline 9 & 47 & Ic-b & Abdominal mass & - & 0.8 (p.o.) & 1.3 (p.o.) & 90 (р.o.) & - \\
\hline 10 & 67 & IIc & $\begin{array}{l}\text { Abdominal distension } \\
\text { Lower abdominal pain }\end{array}$ & MCT-MT & 13.5 & 2.7 & 43 & 398 \\
\hline 11 & 48 & $\mathrm{IIIb}$ & $\begin{array}{l}\text { Abdominal distension } \\
\text { Abdominal mass }\end{array}$ & МCT-MT & 27.1 & 41 & 250 & 1120 \\
\hline 12 & 29 & IIIc & Abdominal distension & - & 1.6 (p.o.) & 2.5 (p.o.) & 108 (p.o.) & 1427 (р.о.) \\
\hline 13 & 48 & IIIc & Abdominal distension & МCT-MT & 4.1 & 12.3 & 1276 & $<1.0$ \\
\hline 14 & 63 & IV & Lower abdominal pain & MCT-MT & 3.7 (p.o.) & 2.5 (р.o.) & 98 & 23.5 \\
\hline
\end{tabular}

MCT, mature cystic teratoma; MCT-MT, mature cystic teratoma malignant transformation; p.o., post-operative data.

was high and the blood test was repeated, 12 cases $(40 \%)$ showed a normal value in the second examination. Similarly, repeated CEA measurements showed a normal value in $52.9 \%$ of the cases (Table III). Tumor size was repeatedly measured in 20 benign cases with elevated serum SCC/CEA, among which the tumor size remained unchanged in 16 cases, the tumor size increased while the tumor marker decreased to a normal range in 2 cases and the tumor size increased while the tumor marker remained high in only 2 cases.

\section{Discussion}

Mature cystic teratoma of the ovary is the most common benign tumor among reproductive women. Because of the social background, the patient with the disease often chooses non-surgical follow-up or laparoscopic surgery as the treatment. In these cases, however, differential diagnosis and early detection of malignant transformation are important. Malignant transformation arising from mature cystic teratoma occurs in $\sim 1-2 \%$ and the pre-operative diagnosis of malignant transformation is often difficult. However, because ovarian and squamous cell carcinoma of the skin occurs in $\sim 0.008$ 0.012 and $0.0054-0.981 \%$ respectively, mature cystic teratoma is one of the high risk factors of the ovarian malignant tumor $(9,10)$. Our series of 14 cases and other reports clearly indicate that there is a significant difference in the prognosis between cases with stage Ia disease and others. None of the stage Ia cases in our series died of the disease, while 5 out of 7 cases of stage Ic to IV died of the disease. Kikkawa et al reported that the 5-year survival was 94.7, 80 and $12 \%$ for stages I, II and III, respectively (6). Tseng et al showed that the disease-free survival at 2 years was 100,100 , 30 and $0 \%$ for stage I to IV disease, respectively (11). Therefore, it is especially important to seek for a method to diagnose malignant transformation of mature cystic teratoma at a very early stage.

A number of reports showed that the serum tumor marker is useful in distinguishing malignant transformation from benign mature cystic teratoma. Among them, the SCC antigen appears to be the most useful as it is sensitive and specific compared with other markers such as CA125 or CA19-9 (12). However, if restricted to stage Ia cases, it is not sufficiently sensitive or specific. Of the stage I cases, $<50 \%$ showed elevated serum SCC levels $(11,13)$. They suggested that the rise would depend on the stage of the tumor (11) and may not be suitable for the early detection of small tumors since the level depends on the tumor volume (11-13). In this respect, a combination of serum SCC measurements with other markers 
Table II. Operative findings, post-operative treatment and outcome of malignant cases.

\begin{tabular}{|c|c|c|c|c|c|c|c|}
\hline $\begin{array}{l}\text { Patient } \\
\text { No. }\end{array}$ & $\begin{array}{l}\text { Size } \\
(\mathrm{mm})\end{array}$ & Side & $\begin{array}{l}\text { Another } \\
\text { side }\end{array}$ & Pathology & Surgery & Adjuvant therapy & Outcome \\
\hline 1 & 100 & Rt & MCT & SCC & TAH/BSO & None & NED $10 \mathrm{y}$ \\
\hline 2 & 150 & $\mathrm{Lt}$ & MCT & $\mathrm{SCC}$ & $\begin{array}{l}\text { TAH/BSO } \\
\text { Appentectomy } \\
\text { (pre.-hos.) }\end{array}$ & CAP-Fx2 & NED 4 y \\
\hline 3 & 130 & $\mathrm{Lt}$ & Post-ope. & $\mathrm{SCC}$ & TAH/LSO/RS & $\begin{array}{c}\text { TCCx } 2 \\
\text { VAB-6x2 }\end{array}$ & NED 7 y \\
\hline 4 & 200 & $\mathrm{Lt}$ & n.p. & $\mathrm{SCC}$ & $\begin{array}{l}\text { TAH/BSO } \\
\text { (pre.-hos.) }\end{array}$ & $\begin{array}{l}\text { VAB-6x3 } \\
\text { UFT }\end{array}$ & NED $13 \mathrm{y}$ \\
\hline 5 & 230 & Rt & n.p. & $\mathrm{SCC}$ & TAH/BSO/PEN/PAN & None & NED $18 \mathrm{~m}$ \\
\hline 6 & 140 & Rt & n.p. & $\mathrm{SCC}$ & TAH/BSO/PEN/PAN & $\begin{array}{l}\text { IPx1 } \\
\text { DJx2 }\end{array}$ & NED $17 \mathrm{~m}$ \\
\hline 7 & 200 & $\mathrm{Lt}$ & n.p. & TCC & TAH/BSO/OM & $\begin{array}{c}\text { IPx2 } \\
\text { VAB-6x2 }\end{array}$ & NED $10 \mathrm{y}$ \\
\hline 8 & 170 & $\mathrm{Lt}$ & $\mathrm{PCO}$ & $\mathrm{SCC}$ & TAH/BSO & $\begin{array}{c}\text { TCCx } 2 \\
\text { VAB-6x2 }\end{array}$ & NED $19 \mathrm{y}$ \\
\hline 9 & 180 & $\mathrm{Lt}$ & - & Serous & $\begin{array}{l}\text { Supra-TAH/BSO } \\
\text { (pre.-hos.) }\end{array}$ & $\begin{array}{c}\text { VAB-6x2 } \\
\text { Additional TAH } \\
\text { BSO }\end{array}$ & DOD 5 y \\
\hline 10 & 130 & $?$ & No detect & $\mathrm{SCC}$ & TAH/BSO/OM & TAIx2 & DOD $4 \mathrm{~m}$ \\
\hline 11 & 200 & $\mathrm{Lt}$ & MCT & $\mathrm{SCC}$ & $\mathrm{TAH} / \mathrm{BSO} / \mathrm{OM}$ & TCCx 3 & DOD $4 \mathrm{~m}$ \\
\hline 12 & 150 & Rt & Post-ope. & $\mathrm{SCC}$ & $\begin{array}{l}\mathrm{RO} / \text { Appendectomy/IP } \\
\text { (pre.-hos.) }\end{array}$ & $\begin{array}{c}\text { SLO/TAH/OM } \\
\text { IPx1 } \\
\text { VAB-6 }\end{array}$ & NED $7 \mathrm{y}$ \\
\hline 13 & 300 & $\mathrm{Lt}$ & MCT & Clear cell & Supra-TAH/BSO/OM & $\begin{array}{c}\text { IPx2 } \\
\text { CPT11/MMCx4 }\end{array}$ & DOD $10 \mathrm{~m}$ \\
\hline 14 & 100 & $\mathrm{Lt}$ & - & SCC & $\begin{array}{c}\text { Supra-TAH/LSO/ } \\
\text { Resection of sigmoid } \\
\text { colon and transverse } \\
\text { colon }\end{array}$ & - & DOD $4 \mathrm{~m}$ \\
\hline
\end{tabular}

Post-ope., post-resection of mature cystic teratoma; pre.-hos, previous hospital; PCO, polycystic ovary; SCC, squamous cell carcinoma; TCC, transitional cell carcinoma; serous, serous papillary adenocarcinoma; clear cell, clear cell carcinoma; TAH, total abdominal hysterectomy; BSO, bilateral salpingo-oophorectomy; LSO, left salpingo-oophorectomy; RO, right oophorectomy; RS, right salpingectomy; PEN, pelvic lymphdenectomy; PAN, para-aortic lymphadenectomy; OM, omentectomy; SLO, second look operation; IP, intra-peritoneal chemotherapy; TCC, two channel chemotherapy; NED, no evidence of disease; DOD, died of disease; y, year; m, month.

or with clinical factors such as patient age or tumor size may give more sensitivity and/or specificity to the diagnosis. Mori et al reported that the serum SCC level $(>2.5 \mathrm{ng} / \mathrm{ml})$ in combination with the patient's age ( $>40$ years old) is considered to be a suitable marker for the differential diagnosis of malignant transformation (1). Kikkawa et al showed that SCC and CEA levels are suitable markers for the patients aged $\geq 45$ years who have a tumor $>99 \mathrm{~mm}$ in maximal dimension (14). Suzuki et al reported that a combined use of serum SCC with M-CSF appears to be useful in the diagnosis of mature cystic teratoma with malignant transformation (13). In our series of 14 cases, both serum SCC and CEA are at high levels in most of the cases including the early stage and this is consistent with previous reports. Similarly, patient age and tumor size were good indications of the malignant phenotype of the tumor as described in other reports. However, a realistic problem is that combinations of larger numbers of factors tend to improve sensitivity, but decrease specificity. Actually, the patient with benign mature cystic teratoma who had either elevated serum SCC or CEA 


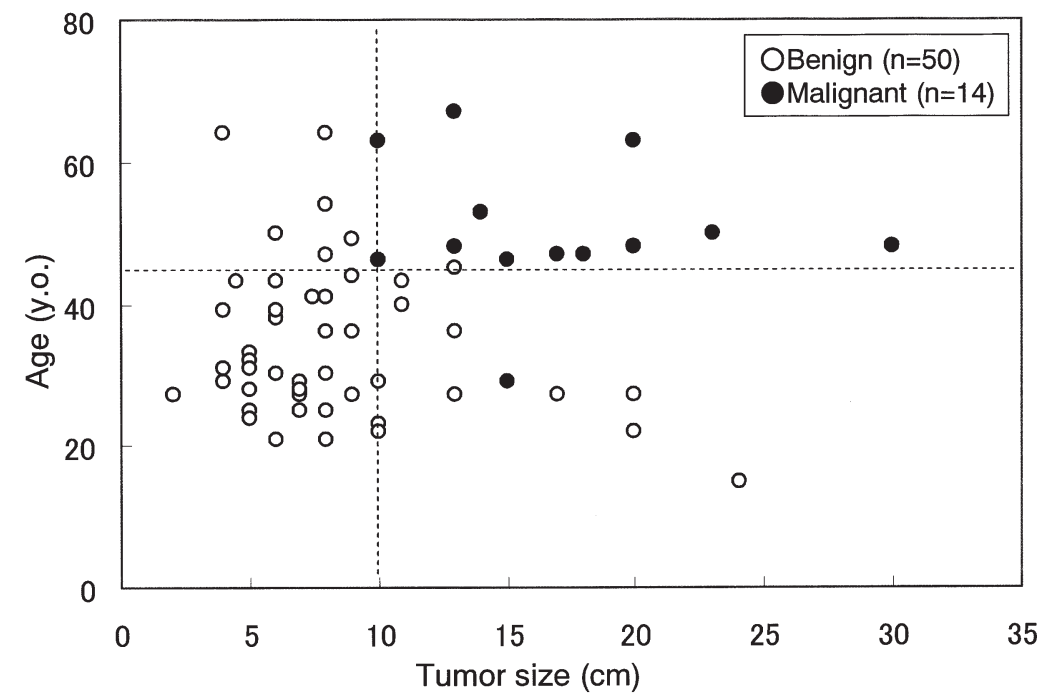

Figure 3. Two-dimensional plots of age of the patients ( $>45$ years old) and tumor size ( $>10 \mathrm{~cm}$ in diameter) among the 50 benign cases and the 14 malignant cases. The frequency of the malignant transformation was $14 \%$ in the age group $>45$ years old, while $0.21 \%$ in the age group $\leq 45$ years old. The sensitivity and the specificity for malignancy using these factors was 92.9 and $98 \%$, respectively.

a) $\operatorname{SCC}(<1.5 \mathrm{ng} / \mathrm{ml})$

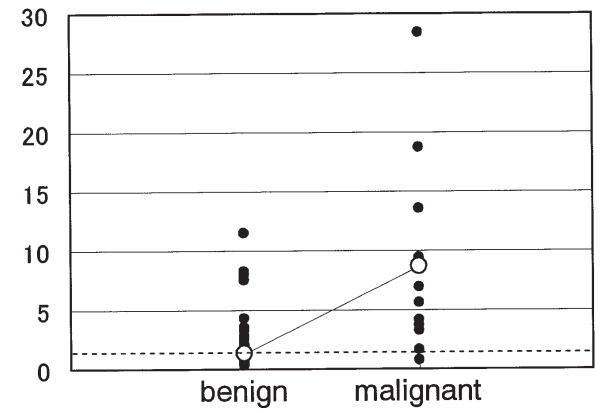

c) $\mathrm{CA} 125(<35 \mathrm{U} / \mathrm{ml})$

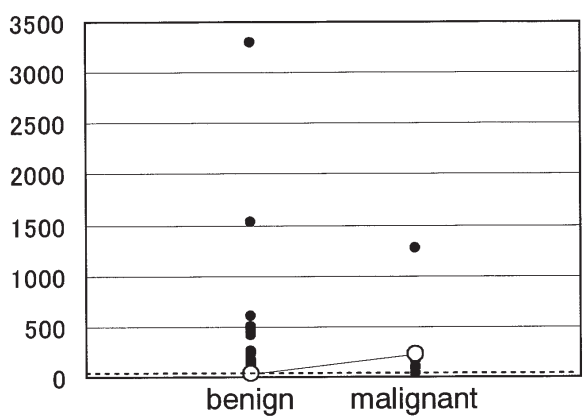

b) CEA (<2.5ng/ml)

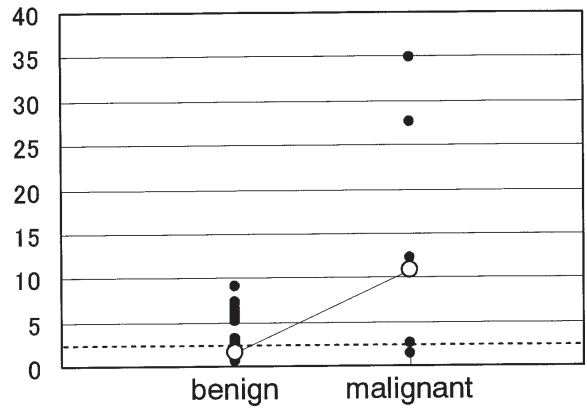

d) CA19-9 $(<37 \mathrm{U} / \mathrm{ml})$

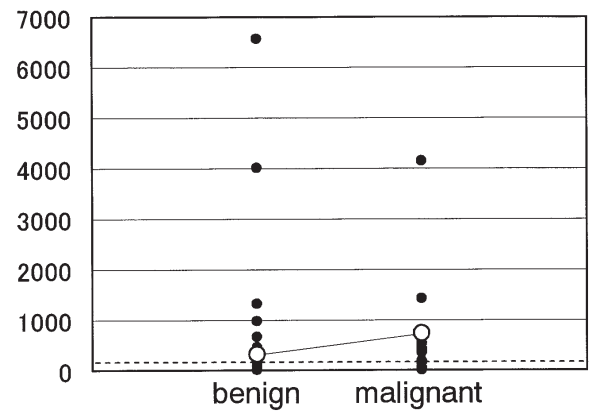

Figure 4. Comparison of the serum tumor marker levels between benign and malignant cases; (a) SCC, (b) CEA, (c) CA125 and (d) CA19-9. The filled plots represent an individual value and the empty plots show the average of the group.

Table III. The comparison of tumor markers of benign cases.

$\begin{array}{ll}\text { Positive } & \begin{array}{l}\text { Negative by } \\ \text { repeat tests }\end{array}\end{array}$

\begin{tabular}{llr}
\hline $\operatorname{SCC}(\mathrm{n}=136)$ & $32(23.5 \%)$ & $12 / 30(40.0 \%)$ \\
CEA $(\mathrm{n}=133)$ & $19(14.3 \%)$ & $9 / 17(52.9 \%)$ \\
CA125 $(\mathrm{n}=138)$ & $57(41.3 \%)$ & $7 / 35(20.0 \%)$ \\
CA19-9 $(\mathrm{n}=139)$ & $66(47.5 \%)$ & $13 / 28(46.4 \%)$ \\
\hline
\end{tabular}

was $32.6 \%$. One of the useful ways to reduce these 'false positive' cases is by repeating blood tests. As shown, about half of the cases revealed a normal value in the repeated examination.

In terms of imaging study, Kido et al reported that mature cystic teratoma with malignant transformation tends to have a solid component that exhibits an extensive transmural extension and direct invasion of neighboring pelvic organs in the MR appearance, but earlier diagnosis is difficult (15). In our series, while all the 7 advanced cases were correctly 
diagnosed as malignant by MR (and CT in some cases), only 2 out of 4 cases and none of 2 cases of stage Ia disease were diagnosed as malignant with MR and CT, respectively. These results suggested that, so far, a CT or MRI is helpful only when characteristic images such as transmural invasion or the spread of malignant tumors become apparent (15). Another report suggested that evaluating the presence or absence of intratumoral blood flow, together with blood flow resistance in tumor vessels using transvaginal color Doppler ultrasound may be more useful in differentiating malignant (SCC) from benign cystic teratomas of the ovary than by measuring serum SCC levels (16).

So far, there are limited reports of malignant transformation from seemingly benign mature cystic teratoma during the follow-up period. The first patient consulted us due to abdominal fullness 5 years after she was first diagnosed as seemingly mature cystic teratoma. The CT and MRI suggested a malignant phenotype different from the previous findings. Surgical removal confirmed squamous cell carcinoma and she has been free of the disease for 17 months after 3 courses of adjuvant docetaxel and carboplatin chemotherapy. The second patient is the youngest in our series and was pregnant when the ovarian cyst was first found. The histology of the tumor was confirmed as benign mature cystic teratoma after surgical removal and the contralateral ovary was normal in intraoperative exploration. Contralateral ovarian swelling was discovered 8 months after the surgery and progressed rapidly within 3 months. Laparotomy resulted in a small residual disease but the patient experienced no recurrent disease after 5 courses of chemotherapy. The third patient was first diagnosed as having a typical dermoid cyst of $4 \mathrm{~cm}$ in diameter in MRI and CT and showed no remarkable change for 3 years. Two years after the last follow-up she was admitted with an enlarged mass indicating bowel perforation. The operation was incomplete and she died of the rapidly progressive disease. The three cases presented here indicate several aspects of the clinical course of malignant transformation from mature cystic teratoma. In cases 2 and 3, malignant transformation and extraovarian spread occurred within 2 years, suggesting that relatively frequent close follow-up (at least twice a year) is necessary even in seemingly benign cases. Case 2 suggests that, even in advanced cases, combinations of maximal cytoreduction and chemotherapy may benefit the patient.

In summary, our data and that of others indicate that in the malignant transformation of mature cystic teratoma the stage of the disease is the most important prognostic factor and, considering the relatively poor chemo-response, early diagnosis is especially important. Since extra-ovarian involvement subsequent to malignant transformation may occur rapidly in some cases, relatively frequent follow-ups should be recommended. Although serum tumor markers, patient age and tumor size are useful factors in distinguishing malignant transformation from mature cystic teratoma, there is no one definite factor or one combination to satisfy both the sensitivity and specificity of the diagnosis. Thus, if malignant transformation was suspected due to serum marker elevation, the employment of other diagnostic methods including imaging study such as US and MRI should be considered. It is particularly important to inform the patient of any risk if present and to give options for the surgical confirmation. In this case, laparoscopic surgery should be avoided as there is a potential risk of intraoperative tumor spillage (17). If the patient desires a conservative follow-up, repeat blood tests and monitoring tumor size are useful in decreasing false positive cases.

\section{References}

1. Mori Y, Nishii H, Takabe K, Shinozaki H, Matsumoto N, Suzuki K, Tanabe H, Watanabe A, Ochiai K and Tanaka T: Preoperative diagnosis of malignant transformation arising from mature cystic teratoma of the ovary. Gynecol Oncol 90: 338-341, 2003.

2. Koonings PP, Campbell K, Mishell DR Jr and Grimes DA: Relative frequency of primary ovarian neoplasms: a 10-year review (Review). Obstet Gynecol 74: 921-926, 1989.

3. Pantoja E, Rodriguez-Ibanez I, Axtmayer RW, Noy MA and Pelegrina I: Complications of dermoid tumors of the ovary. Obstet Gynecol 45: 89-94, 1975.

4. Peterson WF, Prevost EC, Edmunds FT, Hundley JM Jr and Morris FK: Benign cystic teratomas of the ovary; a clinicostatistical study of 1,007 cases with a review of the literature. Am J Obstet Gynecol 70: 368-382, 1955.

5. Stamp GW and McConnell EM: Malignancy arising in cystic ovarian teratomas. A report of 24 cases. Br J Obstet Gynaecol 90: 671-675, 1983.

6. Kikkawa F, Ishikawa H, Tamakoshi K, Nawa A, Suganuma N and Tomoda Y: Squamous cell carcinoma arising from mature cystic teratoma of the ovary: a clinicopathologic analysis. Obstet Gynecol 89: 1017-1022, 1997.

7. Norris HT and O'Connor DM: Pathology of malignant germ cell tumors of the ovary. In: Gynecologic Oncology, 2nd edition, Coppleson M (ed). Churchill-Livingstone, New York, pp917934, 1992.

8. O'Connor D: Ovary-germ cell tumors. In: Clinical Gynecological Pathology. 1st edition, Hernandez E, Atkinson B (eds). W.B. Saunders, Philadelphia, pp463-500, 1996.

9. Tsukuma H: Progress Report of the Research Group for Population-based Cancer Registration in Japan, 2002.

10. Hughes MC, van der Pols JC, Marks GC and Green AC: Food intake and risk of squamous cell carcinoma of the skin in a community: The Nambour skin cancer cohort study. Int $\mathbf{J}$ Cancer 119: 1953-1960, 2006.

11. Tseng CJ, Chou HH, Huang KG, Chang TC, Liang CC, Lai CH, Soong YK, Hsueh S and Pao CC: Squamous cell carcinoma arising in mature cystic teratoma of the ovary. Gynecol Oncol 63: 364-370, 1996.

12. Tangjitgamol S, Manusirivithaya S, Sheanakul C, Leelahakorn S, Thawaramara T and Jesadapatarakul S: Squamous cell carcinoma arising from dermoid cyst: Case reports and review of literature (Review). Int J Gynecol Cancer 13: 558-563, 2003.

13. Suzuki M, Kobayashi H, Sekiguchi I, Konnai K, Terao T and Sato I: Clinical evaluation of squamous cell carcinoma antigen in squamous cell carcinoma arising in mature cystic teratoma of the ovary. Oncology 52: 287-290, 1995.

14. Kikkawa F, Nawa A, Tamakoshi K, Ishikawa H, Kuzuya K, Suganuma N, Hattori S, Furui K, Kawai M and Arii Y: Diagnosis of squamous cell carcinoma arising from mature cystic teratoma of the ovary. Cancer 82: 2249-2255, 1998.

15. Kido A, Togashi K, Konishi I, Kataoka ML, Koyama T, Ueda H, Fujii S and Konishi J: Dermoid cysts of the ovary with malignant transformation: MR appearance (Review). AJR Am J Roentgenol 172: 445-449, 1999.

16. Emoto M, Obama H, Horiuchi S, Miyakawa $\mathrm{T}$ and Kawarabayashi T: Transvaginal color Doppler ultrasonic characterization of benign and malignant ovarian cystic teratomas and comparison with serum squamous cell carcinoma antigen. Cancer 88: 2298-2304, 2000.

17. Wang PH, Yen MS, Juang CM, Chen YJ, Chao HT and Yuan CC: Intraperitoneal cancer spread after laparoscopic cystectomy for mature teratoma with malignant transformation. Eur J Gynaecol Oncol 23: 131-132, 2002. 